\title{
HEALTH GAIN FOR THE CHILDREN AND YOUTH OF CENTRAL SYDNEY: A STRATEGIC PLAN
}

\section{Garth Alperstein}

Community Paediatrician, Community Health Services, Central Sydney Area Health Service

\section{Victor Nossar}

Service Director, Department of Community Paediatrics, South Western Sydney Area Health Service

T he NSW Government's decision to relocate the Royal Alexandra Hospital for Children (one of Sydney's tertiary children's hospitals) from the inner city to the western area of Sydney in November 1995 precipitated the need to develop a strategic plan for children and youth in the Central Sydney Area. The purpose was to determine what new services should be established. This article describes the conceptual framework underpinning the development of this strategic plan and the broad outcomes of the process.

\section{NATIONAL HEALTH PRIORITIES FOR CHILDREN AND YOUTH}

National health priorities provided the framework and direction for the development of this local strategic plan for child and youth health services. Health goals and targets for Australian children and youth set priorities for child health in $1992 .{ }^{1}$ It was followed by the release of the national government policy, The health of young Australians, ${ }^{2}$ which endorsed these priorities and was adopted by Australian Health Ministers Advisory Council in 1995. In 1993 the NSW Health Department took a complementary direction in health service development, focusing on population health outcomes and intersectoral collaboration to achieve maximum health gain for the people of NSW.

\section{THE STRATEGIC PLANNING PROCESS}

The strategic planning process for Central Sydney took a population-health-outcomes focus from the beginning. The approach used was adapted from the work of the Welsh Health Planning Forum for the National Health Service in Wales, which is described in Protocol for investment in health gain. Maternal and early child health. ${ }^{3}$

The aim of the Central Sydney strategic plan was to consider the health status of the local population and then any evidence-based interventions to provide solutions for high-priority health needs. ${ }^{4}$ Central Sydney has adopted the World Health Organization's definition of health: 'not only the absence of disease, but also the physical, emotional, social and spiritual wellbeing of the individual and the community'. The strategic plan acknowledged the influence that politics, economics and the environment have upon health and sought to include the other services and organisations that contribute to the health and wellbeing of the community.
Consequently, the strategic plan for child and youth health services in Central Sydney is explicitly:

- outcome oriented-focusing on the national health goals and targets for Australian children and youth to set priorities for health service action

- evidence based-using data describing the health status of the population and research about health interventions

- focused on equity and social justice-identifying groups in the population that have greater need for health service intervention because of relative social disadvantage

- comprehensive in approach-involving all relevant health and non-health organisations and the community in deciding on the priority of health issues, in planning responses through involvement of the advisory group and working panels, and through community consultations with specific reference groups.

The strategic plan provides a conceptual framework and strategic directions to develop services and target resources to promote health gain for the children and youth of Central Sydney. It was intended that the model could be used by other Area health services and could also provide some key information for those Areas.

Rather than propose radical changes in service delivery over a short term, the strategic plan supports a gradual shift in focus. Health-promotion and illness-prevention programs that have been shown to be effective and that are capable of addressing the high-priority health needs of the community over the longer term will be balanced against the need for acute health care services. To ensure community support, the strategic plan was developed in collaboration with the local community, and consensus was reached regarding the approach taken.

Consideration of the strategic plan shows that there needs to be greater emphasis on health-promotion and illnessprevention activities if health gain for the population as a whole is to be achieved and growth in expenditure on hospital and clinical treatment services is to be moderated. The commitment of Central Sydney Area Health Service to improving health outcomes for the children and youth of Central Sydney can be seen in the development and endorsement of this strategic plan.

\section{REFERENCES}

1. Health goals and targets for Australian children and youth. Canberra: Child, Adolescent and Family Health Service and Department of Community Services and Health, 1992.

2. The health of young Australians. A national health policy for children and young people. Canberra: Australian Government Publishing Services, 1995.

continued on p. 110 


\section{COCHRANE COLLABORATION}

Conversely, if there was good evidence that a strategy had low efficacy or was ineffectual, and that activity was being implemented at that time by CSAHS or other services, this would indicate that there was an opportunity to reorient the resources being used by that service (for example, distraction hearing testing of all seven-month-old babies).

\section{CONCLUSION}

In the final analysis, it was recognised that not all interventions lent themselves to this type of evidencebased evaluation (especially not the interventions of a community development type). The relevance and importance of these kinds of interventions need to be assessed by other means than the application of this kind of evidence-based methodology. As Sackett stated, 'evidence based medicine is not restricted to randomised controlled trials and meta-analyses. It involves tracking down the best external evidence with which to answer the clinical question'. ${ }^{1}$ He particularly cautioned against purchasers and managers using evidence-based medicine as a means to cut health care costs. In fact, the adoption of the most efficacious interventions to maximise both quality and quantity of health outcomes could increase costs.

This process has proved to be useful in identifying areas of practice where changes in services could achieve improved health, as well as highlighting those areas of practice where additional strategies or services are required but may not yet be in place.

\section{REFERENCES}

1. Sackett DL, Rosenberg, MWC, Gray JAM, Haynes RB, Richardson WS. Evidence based medicine: what it is and what it isn't. BMJ 1996; 312: 71-72.

2. Alperstein G, Thomson J, Crawford J. Health gain for children and youth of Central Sydney. Strategic plan. Sydney: Central Sydney Area Health Service, NSW Health Department, 1996. ISBN 0731300297.

3. Canadian Task Force on the Periodic Health Examination, Minister of Supply and Services Canada. Canadian guide to clinical preventive health care. Ottawa: Canada Communication Group Publishing, 1994.

4. Welsh Health Planning Forum. Protocol for investment in health gain. Maternal and early child health. Cardiff: Welsh Office NHS Directorate, 1991. it

\section{HEALTH GAIN FOR THE CHILDREN AND YOUTH OF CENTRAL SYDNEY}

continued from p. 108

3. Welsh Health Planning Forum. Protocol for investment in health gain. Maternal and early child health. Cardiff: Welsh Office NHS Directorate, 1991.

4. Alperstein G, Thomson J, Crawford J. Health gain for children and youth of Central Sydney. Strategic plan. Sydney: Central Sydney Area Health Service, NSW Health Department, 1996. ISBN 0731300297.

\section{Katrina Williams}

Paediatrician, Clinical Epidemiology Unit, New

Children's Hospital, Westmead

The Cochrane Collaboration was established in 1993, with the aim of preparing, maintaining and disseminating systematic reviews of the effectiveness of health care. It is expected that systematic reviews of the available evidence will become the first step in creating policies, changing practice and developing appropriate future research.

Development of the collaboration has demanded the personal and financial commitment of large numbers of individuals (clinicians, academics, consumers and policy makers) and organisations (governments, research agencies and charitable institutions) internationally. Currently the Cochrane database collects systematic reviews of randomised and controlled trials.

\section{THE CHILD HEALTH FIELD}

A child health field was proposed at the 4th International Cochrane Colloquium because of a perceived need for more reviews in the area of child health.

The aim of the child health field is to promote the interests of children within the collaboration by undertaking reviews that address questions that are important for clinicians and parents in a form that is easily translated into policy and practice. Activities include promoting and publicising the field to relevant professionals, consumers and professional bodies. A child health field database of references is currently being developed.

While the Cochrane centres are responsible for training, the child health field will also take on a content-relevant training role. In Australia, training has already been established through the Centre for Community Child Health \& Ambulatory Paediatrics in conjunction with the Department of Biostatistics and Epidemiology of the University of Melbourne, and so far has been provided at the Royal Children's Hospital in Melbourne. In addition, those in the child health field have identified areas within child health where existing review groups will not serve required needs. A planning meeting for a review group on developmental, psychosocial and learning problems was held in 1997 in an attempt to fill one such area of need.

\section{HOW TO BECOME INVOLVED?}

Clinicians can become involved in the Cochrane effort in two ways: by becoming users of reviews on clinically relevant areas or by undertaking reviews themselves. To undertake a review requires training, as well as consultation with the review group most relevant to the chosen topic. A commitment must be made to update the review on a yearly basis, for life. This may sound onerous, but in reality, it can be passed on to another reviewer. It is expected that, in future, review group administrators will look for any new trials on topics registered with them and pass them directly to the reviewers. 